\begin{tabular}{|c|c|}
\hline III Simpósio Paranaense de Modelagem. & Artigo: 15 \\
\hline ISSN $-1984-7521$ & Páginas: 108-112 \\
\hline
\end{tabular}

\title{
DINÂMICA DE REDES DE TROCADORES DE CALOR AFETADAS PELO ACÚMULO DE INCRUSTAÇÕES: ESTUDO DE CASO
}

\author{
Carolina B. Carvalho ${ }^{1 *}$, Esdras P. Carvalho ${ }^{1}$, Mauro A. S. S. Ravagnani ${ }^{1}$ \\ 1 - Universidade Estadual de Maringá (UEM), Programa de Pós-Graduação em Engenharia Química - \\ Maringá - PR - Brasil \\ Email:pg53590@uem.br
}

Resumo - Redes de trocadores de calor (RTC) exercem um papel de suma importância na operação e custo global de um processo. A síntese e otimização de RTC tornaram-se, portanto, assuntos amplamente discutidos pela literatura. Um dos principais fatores que influenciam a eficiência energética de uma rede é o acúmulo de incrustações nas superfícies de troca térmica. Além de diminuírem a capacidade total de troca de calor de uma rede, as incrustações afetam diretamente a dinâmica do processo como um todo, podendo levar à instabilidades no sistema de controle. $\mathrm{O}$ assunto, no entanto, pode ser considerado uma lacuna no estudo de RTC. Modelos dinâmicos que descrevam adequadamente o sistema, aliados com dados de fatores de incrustação $\left(R_{\mathrm{f}}\right)$ em função do tempo, são escassos e limitados em escopo. Dessa forma, o presente trabalho visa contribuir com um estudo dinâmico de RTC afetadas pelo acúmulo de incrustações, avaliando a influência do Rf na temperatura final do sistema e propondo métodos que possam ser utilizados como ferramenta de auxílio em tomadas de decisão no âmbito industrial. Resultados preliminares mostram que o campo de estudo é promissor e possui vertentes a serem exploradas.

Palavras-Chave: Redes de Trocadores de Calor; Incrustações; Modelos Dinâmicos

\section{Introdução}

Redes de trocadores de calor (RTC) são utilizadas, principalmente, para reduzir o consumo energético de uma planta de processo, maximizando a troca térmica entre as correntes de processo que precisam receber ou perder energia na forma de calor.

Um dos problemas mais recorrentes nas RTC é o acúmulo de incrustações que se depositam na superfície de troca térmica, exigindo a instalação de equipamentos superdimensionados, aumentando o uso de utilidades externas para suprir a diminuição da recuperação de energia pelos equipamentos e aceitando a redução do volume produzido devido às intervenções para limpeza mais frequentes, embutindo seu custo no valor final do processo (1).

A síntese de RTC é um assunto amplamente discutido pela literatura. Destaca-se, nesse âmbito, a síntese de RTC envolvendo o projeto detalhado dos trocadores de calor (2). Os autores propuseram a topologia ótima da RTC considerando o projeto dos equipamentos de troca térmica incluindo o fator de incrustação e os limites para queda de pressão, de acordo com padrões internacionais da TEMA (Tubular Exchangers Manufactures Associoation) (3).

As metodologias tradicionais de projeto e monitoramento de trocadores de calor utilizam fatores de incrustação fixos para descrever a resistência adicional à transferência de calor gerada pela presença de depósitos (isto é, valores tabelados de resistência à incrustação, $\left.R_{f}\right)$. No entanto, a incrustação é um processo intrinsecamente dinâmico, que leva a uma degradação gradual do desempenho térmico dos trocadores de calor (4) e, consequentemente, afeta diretamente o desempenho de uma RTC em função do tempo. 
Face a isso, o presente trabalho visa contribuir com um estudo dinâmico de redes de trocadores de calor afetadas pelo acúmulo de incrustações, através da simulação de sistemas modelados a parâmetros concentrados para avaliar o desempenho da RTC em função do tempo.

\section{Metodologia}

O modelo proposto por (5) é utilizado neste trabalho. A ideia principal do modelo é dividir o trocador de calor em células de modelagem $(i, j)$, que trocam calor somente entre si através de uma parede de troca térmica. Em cada célula é assumida a hipótese de mistura perfeita, com propriedades físico-químicas constantes, assim como a temperatura.

Dessa forma, a relação de interdependência entre cada célula define a configuração de fluxo do trocador de calor em questão. Expandindo a análise, é possível obter as relações entre os trocadores de calor para uma dada rede utilizando-se do mesmo conceito de células de modelagem. Realizando os balanços de energia no tubo, casco e parede respectivamente, tem-se:

$$
\begin{gathered}
\frac{d T_{t o}}{d t}=\frac{M_{t}}{\rho_{t} V_{t}}\left(T_{t i}-T_{t o}\right)+\frac{h_{f t} n_{b} \pi D_{1} l}{\rho_{t} V_{t} C_{p t}}\left(T_{t w}-T_{t o}\right) \\
\frac{d T_{w}}{d t}=\frac{h_{f t} n_{b} \pi D_{1} l}{\rho_{w} V_{w} C_{p w}}\left(T_{t o}-T_{t w}\right)+\frac{h_{f s} n_{b} \pi D_{2} l}{\rho_{w} V_{w} C_{p w}}\left(T_{s o}-T_{s w}\right) \\
\frac{d T_{s o}}{d t}=\frac{M_{s}}{\rho_{s} V_{s}}\left(T_{s i}-T_{s o}\right)+\frac{h_{f s} n_{b} \pi D_{2} l}{\rho_{s} V_{s} C_{p s}}\left(T_{s w}-T_{s o}\right)
\end{gathered}
$$

Um modelo descrito por funções de transferência fornece a relação dinâmica entre duas variáveis do processo, a variável dependente (variável de saída ou output) e a variável independente (variável de entrada ou input). Para obtenção das funções de transferência, é necessário, portanto, linearizar as Equações (1) e (3) a partir da expansão em série de Taylor (truncada após o termo de primeira ordem em torno do ponto em estado estacionário). Posteriormente, sistema linear obtido é resolvido obtendo-se, para cada célula $(i, j)$, oito funções de transferência (6).

Definindo o sub-índice $f$ para coeficientes de película $(h)$ em condições de incrustação, as seguintes relações são usadas para calcular seus valores após certos períodos de operação:

$$
\begin{aligned}
& h_{f s}=\frac{h_{s}}{h_{s} R_{f s}+1} \\
& h_{f t}=\frac{h_{t}}{h_{s} R_{f t}+1}
\end{aligned}
$$

A RTC é, então, implementada no MATLAB/Simulink através de um subsistema com as devidas funções de transferência, estabelecendo as relações adequadas para cada célula 
em malha aberta. Essa pode ser considerada uma nova metodologia para avaliação do efeito de incrustações em RTC.

A análise foi realizada em cinco períodos de operação, variando $R_{f}$ a partir de sua condição inicial (equipamento limpo) até a condição de máxima incrustação para a qual foi projetado $\left(100 \% R_{f}\right)$. Então, aplica-se uma perturbação degrau de $10 \%$ na vazão mássica do casco, avaliando a temperatura de saída do fluido que escoa pelos tubos.

\section{Resultados e Discussão}

O estudo de caso apresentado por este trabalho baseia-se numa RTC otimizada e com os equipamentos de troca térmica previamente projetados detalhadamente (2).

A RTC é composta por quatro correntes de processo (duas quentes e duas frias) e a melhor configuração encontrada consiste em dois trocadores de calor em série (Figura 1).

Foi avaliada a temperatura de saída do fluido frio $(\mathrm{C} 1)$ pelo trocador E1 a partir da aplicação de uma perturbação degrau na vazão mássica do fluido quente $\mathrm{H} 2$. O valor de $R_{f}$ foi variado de modo a simular o acúmulo de incrustações em função do tempo e, dessa forma, avaliar como esse fator afeta a temperatura de saída do processo de modo geral.

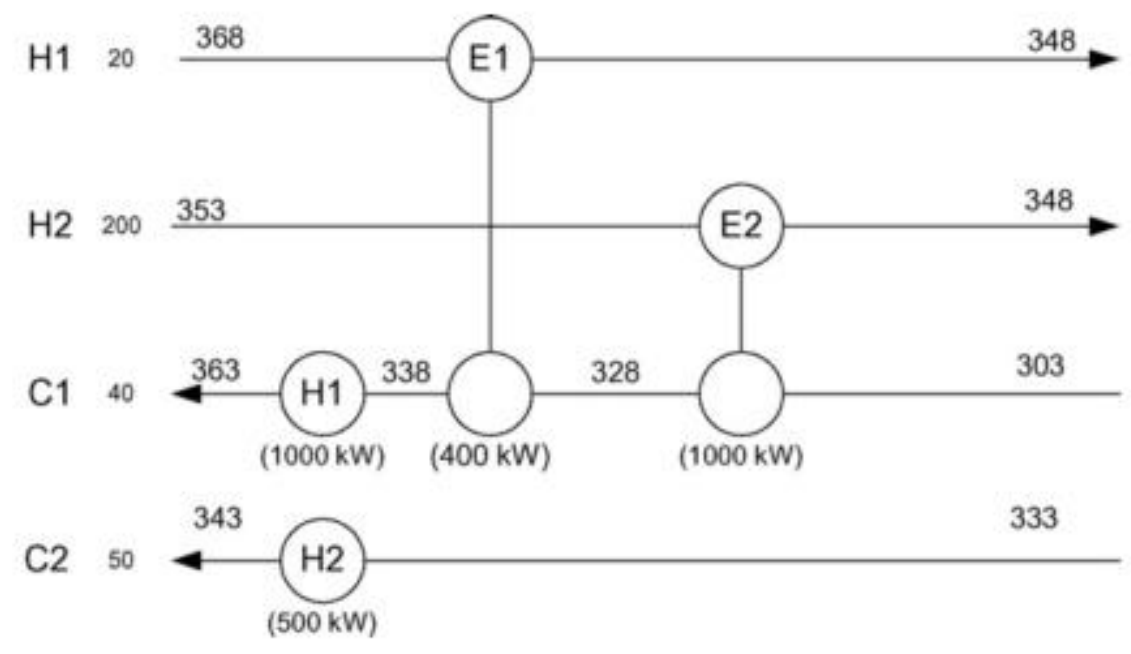

Figura 1 - Configuração da RTC implementada no Simulink

Fonte: Adaptado de (2)

A Figura 2 mostra graficamente os resultados preliminares obtidos. É possível notar que a eficiência do traçador de calor é consideravelmente afetada pelo fator de incrustação, não sendo capaz de atender à demanda energética pelo qual foi previamente projetado. 


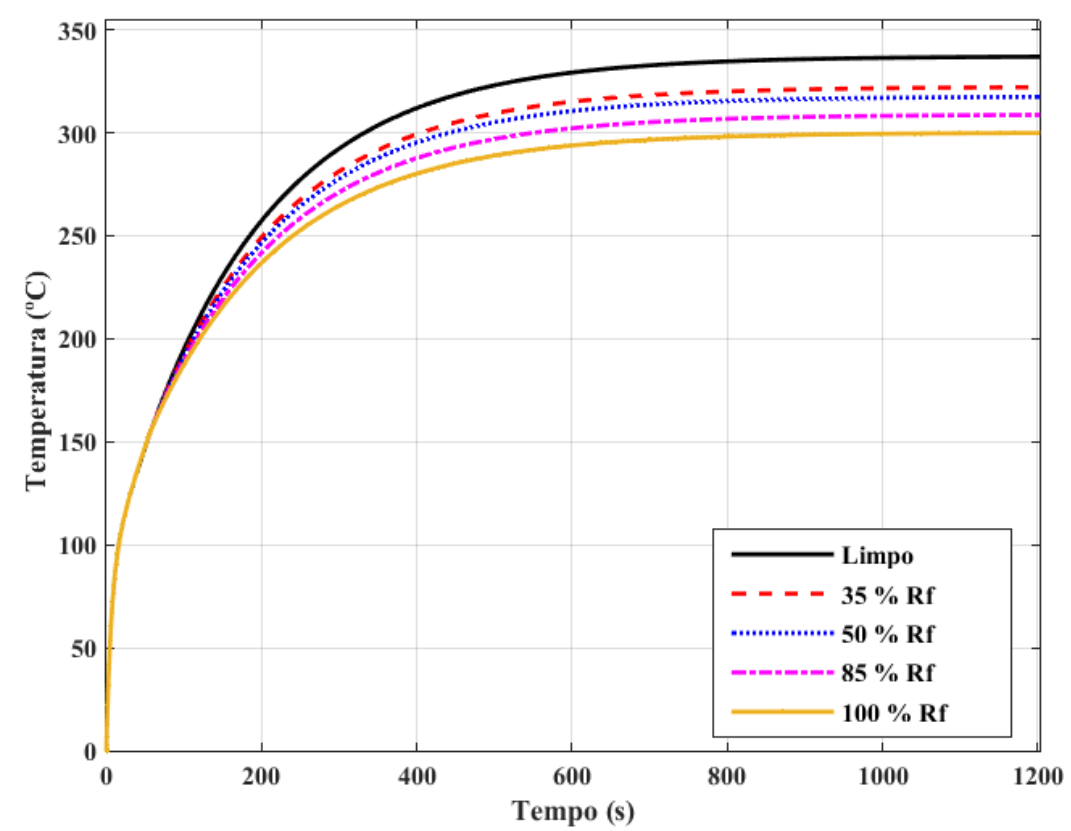

Figura 2 - Resposta em malha aberta para diferentes períodos de operação da RTC

Em seguida, na Tabela 1, é possível notar que a temperatura de saída do fluido frio cai cerca de $35 \mathrm{~K}$ quando o fator de incrustação atinge o valor máximo em relação à condição inicial de operação. É importante ressaltar que, dependendo do processo que esta sendo simulado, tal variação pode não ser aceitável para determinados padrões de qualidade do produto final, exigindo uma intervenção para limpeza ou a implantação de um resfriador para atender à demanda de temperatura da corrente $\mathrm{C} 1$.

Tabela 1 - Temperatura final em função do fator de incrustação

\section{Temperatura Final (K) Fator de Incrustação (\%)}

\begin{tabular}{|c|c|}
\hline 336,4 & 10 \\
\hline 321,6 & 35 \\
\hline 317,0 & 50 \\
\hline 308,2 & 85 \\
\hline 299,5 & 100 \\
\hline
\end{tabular}

\section{Conclusões}

É notória uma lacuna na literatura no que diz respeito à simulação dinâmica de RTC afetadas pelo acúmulo de incrustações. Os resultados apresentados mostraram que essa análise pode ser fundamental para definição de intervenções para limpeza ou topologias diferenciadas para cada tipo de depósitos. 
A RTC simulada teve sua área de troca térmica devidamente projetada para atender à demanda energética do processo até a condição máxima de incrustação. No entanto, a análise dinâmica mostra que, partindo-se de condições de superfície de troca térmica limpa, a RTC pode não atender aos requisitos de determinados processo.

Uma análise mais rigorosa pode ser realizada considerando-se o sistema de controle implementado na rede, bem como a influência do fator de incrustação na sintonia de determinados controladores, visando mitigar os efeitos indesejáveis dos depósitos na qualidade do sinal de saída do processo.

\section{Agradecimentos}

Os autores agradecem o apoio financeiro da CAPES e CNPq para realização deste projeto.

\section{Bibliografia}

1. Markowski, M., Trafczynski, M. e Urbaniec, K. Identification of the influence of fouling on the heat recovery in a network of shell and tube heat exchangers. Applied Energy. 2013, Vol. 102, pp. 755-764.

2. Ravagnani, M.A.S.S, Silva, A.P e Andrade, A.L. Detailed equipment design in heat exchanger networks synthesis and optimisation. Applied Thermal Engineering. 2003, Vol. 23, pp. 141-151.

3. TEMA. Tubular Exchangers Manufacters Association. New York : s.n., 2007.

4. Diaz-Bejarano, E., et al. Organic and inorganic fouling in heat exchangers - Industrial case study: Analysis of fouling state. Applied Energy. 2017, Vol. 206, pp. 1250-1266.

5. Varbanov, P. S, Klemeš, J. J e Friedler, F. Cell-based dynamic heat exchanger models-Direct determination of the cell number and size. Computers \& Chemical Engineering. 2011, Vol. 35, pp. 943-948.

6. Carvalho, C. B, Carvalho, E. P e Ravagnani, M. A. S. S. Dynamic Analysis of Fouling Buildup in Heat Exchangers Designed According to TEMA Standards. Industrial \& Engineering Chemistry Research. XX, 2018, pp. XX-XX. 